\title{
Intertextualidades cinematográficas nas histórias em quadrinhos d'Os Trapalhóes: contribuições para a educação
}

\author{
Intertextuality in motion comic's Trapalhões: contributions to \\ education
}

\section{Rafael Jose Bona}

Mestre em Educação pela Universidade Regional de Blumenau (FURB) e especialista em Cinema pela Universidade Tuiuti do Paraná (UTP) e em Fotografia pela Universidade do Vale do Itajaí (UNIVALI), professor do Departamento de Comunicação da Universidade Regional de Blumenau (FURB), Blumenau, SC - Brasil, e-mail: bona.professor@gmail.com

\begin{abstract}
Resumo
Nos últimos anos as histórias em quadrinhos (HQs) ficaram cada vez acessíveis para as pessoas graças à internet e ao baixo preço. Em diversas escolas do país, professores dos mais diversos níveis de ensino (do básico ao universitário) começaram a enxergar viabilidades educativas por meio delas. Este artigo tem o objetivo de contribuir para a utilização de HQs nos anos iniciais do Ensino Fundamental, propondo atividades, a partir das Revistas em quadrinhos d'Os Trapalhões (As Aventuras dos Trapalhões), editada de 1989 a 1994 (num total de 51 edições), que trabalhavam com intertextualidades cinematográficas, parodiando filmes dos mais diversos gêneros e enredos. Espera-se que as contribuições relatadas neste artigo possam despertar o interesse dos educadores e que contribuam na formação cultural das crianças e dos adolescentes.
\end{abstract}

Palavras-chave:Histórias em Quadrinhos. Cinema. Educação. Os Trapalhões. 


\begin{abstract}
In recent years the comics (comics) have become increasingly accessible to people through the internet and low price. In many schools across the country, teachers of all levels of education (from primary to university) educational viability began to see through them. This article aims to contribute on the use of comics in the early years of elementary school, offering activities, from The Comics d'Trapalhöes (The Adventures of Trapalhöes), published from 1989 to 1994 (a total of 51 issues), who worked with cinematic intertextuality, parodying films from various genres and plots. It is hoped that contributions reported in this article may pique the interest of educators and contribute in shaping cultural children and adolescents.
\end{abstract}

Keywords: Comics. Movies. Education.The Trapalhões.

\section{Introdução}

Diante do atual cenário de convergências midiáticas e do desenvolvimento tecnológico, nos quais os estudantes estão mais conectados e interados, é cada vez mais comum a preocupação dos professores acerca da utilização de diversos materiais complementares, tanto na educação básica quanto na superior, para o aprimoramento e a contribuição do ensino e da aprendizagem em sala de aula. Isso já pode ser notado há décadas, com a utilização de diversas mídias como vídeos, filmes, fotografias, revistas, jornais, entre outros que contribuem de uma forma ou de outra no processo educativo.

Muitos comportamentos, atitudes, estilos de vida e valores foram determinados na sociedade graças ao constante crescimento e desenvolvimento tecnológico no qual os meios de comunicação social se tornaram cada vez mais presentes na vida do ser humano. Com a exposição diária às novas formas de expressão e comunicação as pessoas começaram a se acostumar cada vez mais com as novas tecnologias que vieram colaborar, em alguns casos, no processo de ensino e aprendizagem (PACHECO, 1991).

Dentro dessa realidade, entram também as HQs que ficaram cada vez acessíveis (pela internet e pelo baixo preço) nas escolas por parte dos alunos e por parte dos professores que começaram a enxergar viabilidades educativas por meio delas.

De acordo com Barbosa, Ramos, Vilela, Rama e Vergueiro (2004), a representação dos quadrinhos como meio de comunicação tem grande penetração popular. No mundo todo há uma quantidade vasta de títulos e gêneros que são adquiridos e consumidos por um público fiel. "A produção, divulgação e comercialização, organizada em escala industrial, permitiu a profissionalização das várias etapas de sua elaboração, possibilitando-lhes atingir tiragens astronômicas" (BARBOSA et al., 2004, p. 7).

De alguns anos para cá, a prática da utilização de HQs pelos docentes têm se tornado cada vez mais comum. Isso pode ser percebido nos recentes estudos desenvolvidos em nível stricto sensu por Andraus (2006), Bari (2008), Mendonça (2008), D’Oliveira (2009), Vilela (2012), entre muitos outros que discorrem sobre as HQs nas salas de aula. Segundo Santos (2003, p. 1), elas são um "veículo de comunicação visual, além de ser um produto de consumo elaborado pela Indústria Cultural, tem diversas aplicações" que podem servir como um instrumento de transmissão do conhecimento ou uma ferramenta a ser utilizada no ensino e na aprendizagem.

De acordo com Vilela (2012), o perfil do aluno mudou, assim como também mudaram os professores. "Aliás, uma das razões de porque as HQs hoje costumam ser mais bem recebidas na sala de aula é que os professores de hoje não são os mesmos do passado." (VILELA, 2012, p. 40). $\mathrm{O}$ autor argumenta que são docentes de uma outra geração, que lida com problemas específicos da época atual. Isso vem ao encontro do que já disse Santos, quando ressalta que no Brasil há um desinteresse pela leitura, principalmente por parte das novas gerações, e de uma forma preconceituosa é generalizada como consequência dos meios visuais e audiovisuais existentes como a televisão, o videogame etc. Bari (2008) também argumenta sobre essa realidade em relação às novas mídias; porém, essa crise na leitura 
se deu também nas HQs e isso acabou modificando as dimensões do público leitor.

Apesar dessa modificação na realidade, é recente também o crescimento do interesse pela utilização de HQs na educação, que vão de professores de todos os níveis educacionais e que aceitam o incentivo oficial que é oferecido pela Lei de Diretrizes e Bases e pelos Parâmetros Curriculares Nacionais (VERGUEIRO, 2004). Porém, segundo Santos (2003, p. 12), é importante que os educadores "percam o preconceito ainda existente em relação à História em Quadrinhos e passem a considerar este meio de expressão artística como forte aliado na formação dos jovens."

Dentro desse contexto, o artigo $^{1}$ tem o objetivo de contribuir acerca da utilização de HQs na educação básica (anos iniciais do Ensino Fundamental) propondo atividades a partir das Revistas em Quadrinhos d'Os Trapalhöes (As Aventuras dos Trapalhões), editadas de 1989 a 1994 (num total de 51 edições), que trabalham com intertextualidade cinematográfica. Isso poderia despertar o interesse pelas artes e pelo cinema nas crianças a partir das HQs contribuindo para uma formação cultural mais crítica e com a vontade em conhecer os filmes ${ }^{2}$ trabalhados na intertextualidade ${ }^{3}$ de Os Trapalhões.

\section{Histórias em quadrinhos na educação}

No Brasil a pesquisa sobre história em quadrinhos é realizada em diversas universidades com certa frequência. Vergueiro e Santos (2006, p. 1) dizem que:

Grande parte dos trabalhos acadêmicos formais apresentados sobre o tema como dissertações e teses tem se relacionado com as ciências da comunicação, mas também é possível encontrar trabalhos investigativos sobre histórias em quadrinhos nas áreas de Letras, Psicologia, História, Pedagogia e Medicina. Isto ocorre não apenas pelos quadrinhos se constituírem em um dos mais pujantes produtos culturais da comunicação de massa e terem grande popularidade entre a população, mas também por terem despertado o interesse dos pesquisadores da mais diversas áreas.

Dentro do contexto educacional, Vieira e Veloso (2011, p. 692) discorrem que as HQs se tratam de um "gênero textual curto e de rápida absorção por parte do leitor [...] sendo assim pode ser considerado um meio de estimular o aluno a aprender o que é proposto pelo professor". Barbosa et al. (2004) argumentam que graças ao desenvolvimento dos meios de comunicação como o cinema, o rádio, a televisão e, inevitavelmente, os quadrinhos, passaram a receber uma atenção especial dos intelectuais e passaram a ser aceitos como uma forma de manifestação artística e com características próprias. Os autores ainda apontam que o emprego das histórias em quadrinhos já tem devido reconhecimento pela LDB (Lei de Diretrizes e Bases) e pelos PCN (Parâmetros Curriculares Nacionais), conforme síntese exposta no quadro 1.

Cirne (1977) aponta que por muito tempo as histórias em quadrinhos eram tidas como uma literatura prejudicial no desenvolvimento da intelectualidade infantil. "Aos poucos, porém, foi-se verificando a fragilidade dos argumentos daqueles que investiam contra os quadrinhos: uma nova base metodológica de pesquisas culturais conseguiu estruturar a sua evolução crítica" (CIRNE, 1977, p. 11) e as HQs começaram a ser vistas como potencial fenômeno dentro das culturas midiáticas. Essas referidas mídias, segundo Belloni (2010,p. 61), podem ser consideradas "dispositivos extremamente eficazes de socialização das novas gerações, não apenas porque ocupam a

\footnotetext{
1 Este artigo se trata de fragmentos de uma pesquisa realizada no Grupo de Pesquisa Estudos Midiáticos Regionais (Linha Mídia e Desenvolvimento Regional) da FURB.

2 Rizzo Júnior (2011), em sua Tese de Doutorado, argumenta sobre a possibilidade de despertar cada vez mais o interesse pelo audiovisual entre os alunos da educação básica, pois se trata de um público que está em constante contato com as convergências midiáticas.

3 Intertextualidade são "as relações entre textos que ocorrem quando uma obra se refere a outra, ou aos seus personagens, expressões, situações ou idéias” (JENKINS, 2009, p. 382).
} 
Quadro 1 - Desempenho das HQs em sala de aula

\begin{tabular}{l}
\hline Os estudantes querem ler os quadrinhos \\
\hline Palavras e imagens, juntos, ensinam de forma mais eficiente \\
\hline Existe um alto nível de informação nos quadrinhos \\
\hline As possibilidades de comunicação são enriquecidas pela familiaridade com as histórias em quadrinhos \\
\hline Os quadrinhos auxiliam no desenvolvimento do hábito de leitura \\
\hline Os quadrinhos enriquecem o vocabulário dos estudantes \\
\hline O caráter elíptico de linguagem quadrinhística obriga o leitor a pensar e imaginar \\
\hline Os quadrinhos têm um caráter globalizador \\
\hline Os quadrinhos podem ser utilizados em qualquer nível escolar e com qualquer tema \\
\hline
\end{tabular}

Fonte: Síntese de Barbosa et al. (2004, p.21).

quase totalidade do tempo livre das crianças, mas também porque fornecem os conteúdos", e são nesses conteúdos que estão seus heróis e mitos que auxiliam na construção do imaginário, dos valores e das suas representações.

As palavras, as imagens e os vários elementos, combinados de diversas maneiras conseguem produzir determinados sentidos, o que constitui a linguagem dos quadrinhos que começou a ter fins educativos no mesmo século em que elas se popularizaram e começaram a se difundir no mundo todo (MENDONÇA, 2008). Isso vem ao encontro do que diz Bari (2008, p. 215), que há um reconhecimento cada vez maior do valor da leitura de histórias em quadrinhos nos ambientes educacionais por suas "propriedades hibridizadas de sua linguagem, devido aos elementos semânticos de sua matriz visual-verbal",

Assim como qualquer outra narrativa, as histórias em quadrinhos têm como elementos personagens, tempo, espaço e ação. A forma como essa narrativa é realizada, porém, é um tanto peculiar, pois nas HQs os autores narram por meio de uma mistura - ou melhor, uma sobreposição - de imagens e palavras. Assim, para entender a história, o leitor de quadrinhos precisa utilizar suas habilidades interpretativas, tanto visuais quanto verbais (CARVALHO, 2006, p. 41).

Em pesquisa realizada em 2011 (Retratos da Leitura no Brasil), foi constatado que em 46\% das leituras realizadas no Brasil os quadrinhos estão entre as primeiras posições das mais frequentes. A mesma pesquisa aponta que de 2007 para 2011 o número de crianças e adolescentes que leem livros caiu, porém, as que ainda mantêm o hábito da leitura são aquelas que frequentam escolas onde é obrigatória a leitura de determinadas obras.

\section{Diálogos entre o cinema e os quadrinhos d'OS Trapalhóes}

Segundo Guimarães (2010, p. 9), certos críticos acreditam que as "melhores adaptações dos quadrinhos para o cinema sejam as assumidamente traduzidas para a linguagem audiovisual, ou seja, são cinema, antes de tudo, como é o caso dos filmes de super-heróis". A autora ainda ressalta que a fidelidade consiste na preservação da essência das personagens e no contexto nas quais foram criadas.

Cirne (2000) aponta que o cinema e os quadrinhos são mais aproximados pela questão narrativa do que ao discurso e suas imagens.

Se as HQs causaram mais impacto em outros tempos e hoje perdem espaço para meios de expressão de impacto sensorial bem maior, como o cinema, são também fonte de inspiração para esta mesma mídia. As adaptaçóes de argumentos originais dos gibis para as telas crescem ano a ano, arrecadando fortunas nas bilheterias. Mas os quadrinhos continuam sendo um celeiro de ricas elaboraçốes culturais que transitam pela sociedade em diversos níveis de significação e penetração (PATATI; BRAGA, 2006, p. 09). 
Para Nogueira (2010,p. 56), "uma obra nunca existeisolada". O autormenciona que um texto (no caso, uma obra), sempre é encontrada numa rede com vários outros textos que "o comentam, o citam, o refazem, o recuperam, o analisam." Tanto nos cinemas quanto nos quadrinhos essa relação plural e diversificada dos vários textos assumem um papel importante no processo criativo.

Nomercadoeditorial brasileiro de quadrinhos têm se percebido nas últimas três décadas uma quantidade representativa do gênero comédia, publicado para crianças e adolescentes como: Turma da Mônica, Quadrinhos Disney, Os Trapalhöes, Turma do Arrepio, Garfield, Os Flinstones, entre muitos outros. A comédia está presente em diversos segmentos das mídias.

Ramos (2004) aponta que no Brasil existe uma forte tradição da comédia como meio de comunicação audiovisual em forma seriada duradoura (podemos verificar exemplos como Cassetae Planeta Urgente, Zorra Total, A Grande Familia, entre outros) e dentro desse contexto entram Os Trapalhões, grupo cômico formado porquatro integrantes (Didi, Dedé, Mussum e Zacarias), que ao longo de quatro décadas levaram o humor infantil e popular para a televisão, para o cinema e também para as histórias em quadrinhos.

O grupo passou por fases distintas em cada formato midiático, e que também se subdividiam. $\mathrm{Na}$ televisão o grupo teve formação inicial (com diversos integrantes) em 1966; entra na TV Globo em 1977 e permanece até o ano 2000 com programas inéditos e reprises, e desde 1998 com A Turma do Didi (exibido até os dias atuais). No cinema foram produzidos 47 filmes (1965 a 2008), porém com o famoso quarteto foram 22 (1978 a 1990, ano em que falece o Zacarias).

Nos quadrinhos foram três fases. Uma pela Bloch Editores (1976-1987 e, isoladamente, em 1996), outra pela Editora Abril (1988-1994) e outra pela Editora Escala (2004-2011). A primeira fase era baseada em paródias de programas televisivos e super-heróis, heróis de filmes e de desenhos animados. A segunda fase se baseia em paródias de filmes e de personagens com aventuras cômicas do cotidiano. A terceira fase se concentra na personagem principal Didi e sua filha Lili (Figuras 1, 2 e 3). Para melhor visualização de todas fases d'Os Trapalhões em quadrinhos foi elaborado o Quadro 2.

O presente texto se debruça sobre um fragmento da segunda fase da revista $\operatorname{com}$ As Aventuras dos Trapalhöes (1989-1994, 51 edições). De acordo com o siteOs Trapalhões (2012), os desenhos dessa fase foram criados por César Sandoval nos quais os humoristas eram retratados como crianças (os mesmos personagens criados por Sandoval também podiam ser vistos nas aberturas dos filmes do grupo ou em desenhos animados para comerciais de televisão da época).

Apesar do falecimento do Zacarias, em 1990, a revista teve sua publicação editada normalmente. $A s$ Aventuras dos Trapalhöes trabalhavam com um intertexto de filmes, televisão eliteratura. Paródias a filmes famosos eram mais comuns de se ver na literatura em HQ do grupo: Didiana Jones (em relação a Indiana Jones), 2001 Trapalhadas no Espaço (2001: Uma Odisséia no Espaço),

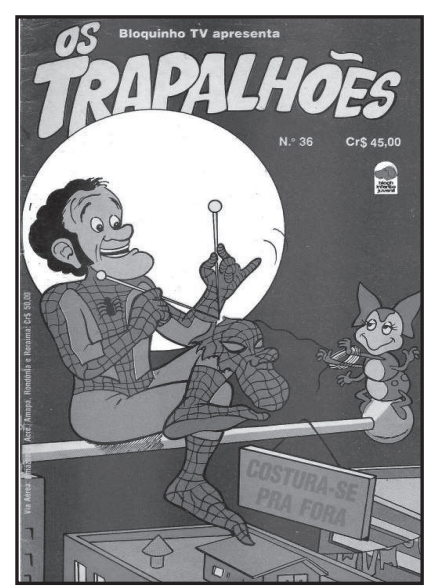

Figura 1 - Fase I

Fonte: Os Trapalhões (2012).

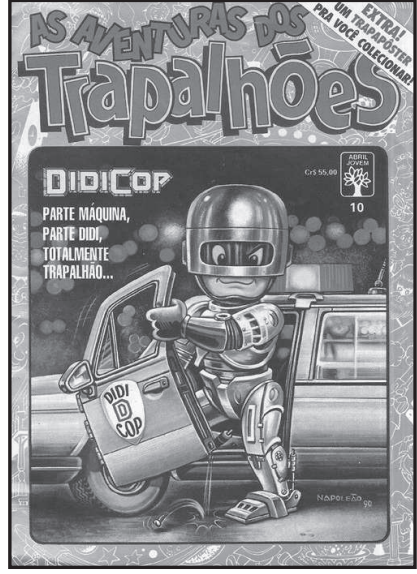

Figura 2 - Fase II

Fonte: As aventuras dos Trapalhões (2012).

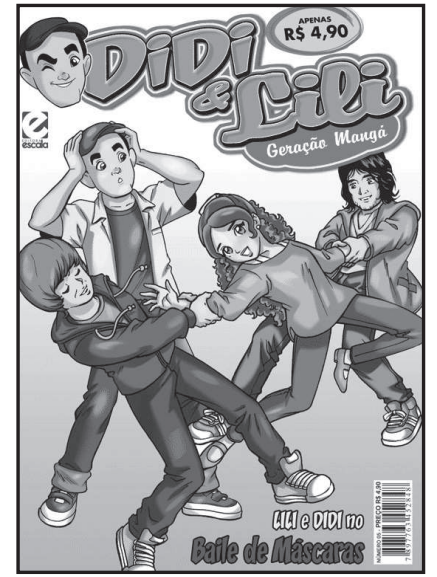

Figura 3 - Fase III

Fonte: Didi \& Lili (2012). 
Quadro 2 - Os Trapalhões em quadrinhos

\begin{tabular}{|c|c|c|c|}
\hline Fase & Título das edições & Período & Total de exemplares \\
\hline $\begin{array}{c}\text { I } \\
\text { Editora Block }\end{array}$ & $\begin{array}{l}\text { Os Trapalhões } \\
\text { Aventuras do Didi } \\
\text { Almanaque Os Trapalhões } \\
\text { Almanaque de Férias (15 Anos de Os Trapalhões) } \\
\text { Almanaque Supertrapalhões } \\
\text { Supertrapalhões } \\
\text { Trapa Suat - Os Trapalhões na Suat } \\
\text { Didi: Passatempos e Quadrinhos } \\
\text { As Aventuras do Didi* }\end{array}$ & $\begin{array}{c}1976-1986 \\
1982-1985 \\
1982-1985 \\
1981-1981 \\
1987-1987 \\
1987-1987 \\
1978-? ? \\
1987-? ? \\
1996-1996\end{array}$ & $\begin{array}{l}83 \\
42 \\
11 \\
02 \\
02 \\
09 \\
05 \\
09 \\
03\end{array}$ \\
\hline $\begin{array}{l}\text { II } \\
\text { Editora Abril }\end{array}$ & $\begin{array}{l}\text { Revista em Quadrinhos dos Trapalhões (Mini Revista Danone) } \\
\text { Os Trapalhões - Revista em Quadrinhos } \\
\text { Almanaque Aventuras dos Trapalhões } \\
\text { Almanaque dos Trapalhões } \\
\text { Aventuras dos Trapalhões (Mini Revista - Suplemento) } \\
\text { Aventuras dos Trapalhões - Especial (Grafic Trapa) } \\
\text { As Aventuras dos Trapalhões (RPG) } \\
\text { As Aventuras dos Trapalhões } \\
\text { Grande Almanaque dos Trapalhões } 25 \text { anos } \\
\text { Trapalhões - Revista em Quadrinhos (Fac-Símile do n. 01) }\end{array}$ & $\begin{array}{l}1988-1988 \\
1988-1993 \\
1990-1994 \\
1988-1990 \\
1992-1992 \\
1991-1991 \\
1993-1993 \\
1989-1994 \\
1991-1991 \\
1991-1991\end{array}$ & $\begin{array}{l}03 \\
76 \\
06 \\
05 \\
03 \\
01 \\
02 \\
51 \\
01 \\
01\end{array}$ \\
\hline $\begin{array}{c}\text { III } \\
\text { Editora Escala }\end{array}$ & $\begin{array}{l}\text { As Aventuras do Didizinho } \\
\text { As Aventuras do Didizinho - Edição Encadernada } \\
\text { Didi e Lili - Geração Mangá }\end{array}$ & $\begin{array}{l}2004-2005 \\
2004-2004 \\
2010-2011\end{array}$ & $\begin{array}{l}20 \\
01 \\
10\end{array}$ \\
\hline
\end{tabular}

Fonte: Pesquisa de campo e Guia dos Quadrinhos (2012).

Máquina Trapalbifera (Máquina Mortífera), Didi Volta Para o Futuro (De Volta Para o Futuro) (Figuras 4 e 5), entre muitos outros.

A lendária história da cena da locomotiva dos Irmãos Lumiére (inventores do cinema), por exemplo, e que fez várias pessoas saírem correndo quando o trem se aproximava (Figura 6), também foi tema da revista em 1992, na edição de número 27 (Figura 7). Isso se torna importante para suscitar o gosto e a curiosidade sobre cinema em crianças dos anos iniciais do Ensino Fundamental, por exemplo. Field (2001, p. 9) afirma que "cada filme a que você assiste transforma-se num processo de aprendizado".

Em outro momento das HQs do quarteto, nota-se a utilização do ícone Charles Chaplin em suas histórias, como, por exemplo, as narrativas que utilizam Didi como o "vagabundo" e seu cachorro e as dificuldades de sobrevivência (como eram parte dos filmes de Carlitos). Os quadrinhos mantinham a questão do cinema mudo (pois nenhum deles possuía os balões com falas como é feito usualmente) (Figura 8). Vergueiro (2004) diz que existe uma relação harmônica entre cinema e quadrinhos, e isso vem de longa data. Os dois surgiram no fim do século XIX e sempre trocaram influências e temas. Muitos sucessos dos quadrinhos, como The Spirit, "beberam fartamente em enquadramentos, ângulos, iluminação e montagem das produções cinematográficas, ao mesmo tempo que diretores de cinema buscaram nas HQs a inspiração para seus filmes." (VERGUEIRO, 2004).

Os Trapalhões, dentro do contexto da relação do cinema e dos quadrinhos, trabalham de forma intertextual na modalidade de paródia. Segundo Nogueira (2010, p. 57),é "uma das modalidades mais comuns que tende a alterar o tom, o propósito ou o gênero de uma

\footnotetext{
${ }^{4}$ O autor a partir de pesquisa empírica e adaptações realizadas com informações extraídas do site: <www.guiadosquadrinhos.com. br>, Acessos intermediários em jul. 2012. (*) Em 1996, a Ed. Bloch relançou a revista com as personagens em formato adulto, porém durou apenas três edições.
} 


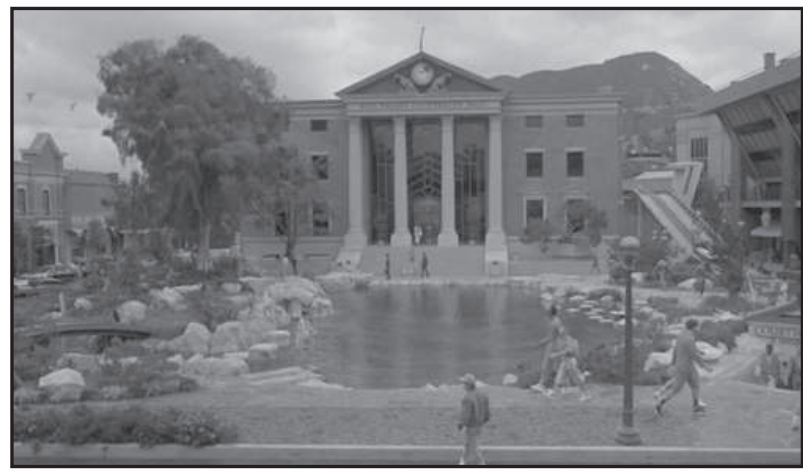

Figura 4 - Frame do filme De Volta Para o Futuro II Fonte: De Volta Para o Futuro II (1989).

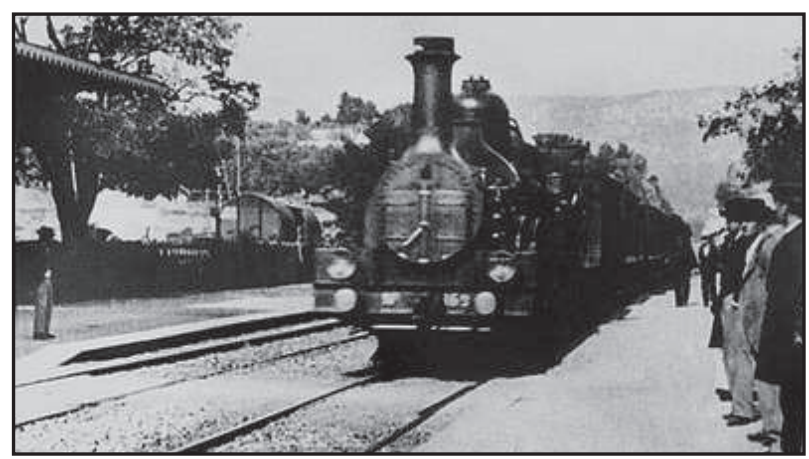

Figura 6 - Frame do filme Chegada do Trem na Estação Fonte: Ilustrada no cinema (2012).

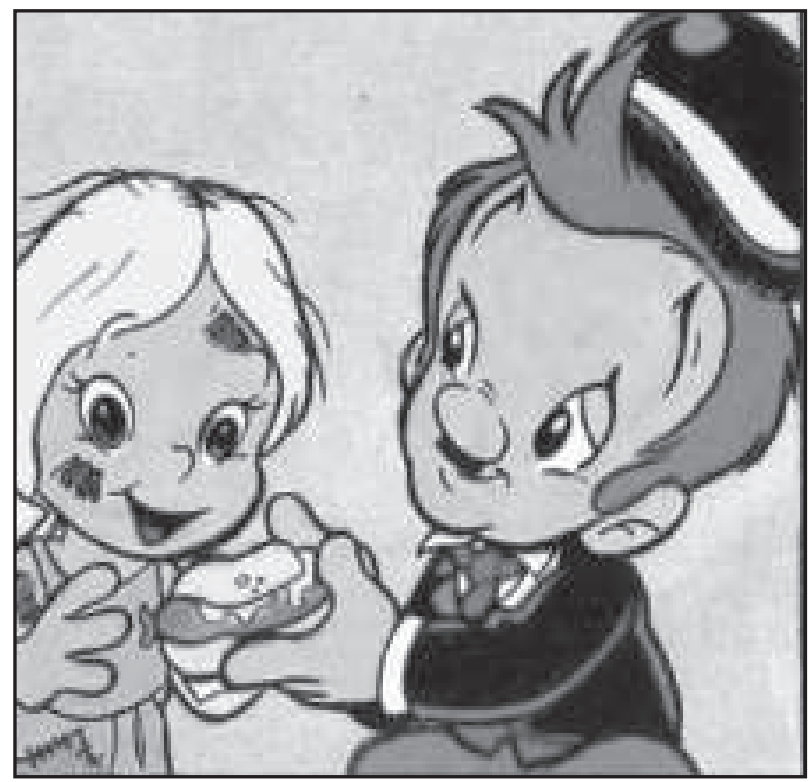

Figura 8 - HQ O Vagabundo Trapalhão Fonte: As Aventuras dos Trapalhões, Ed. 7, p.11.

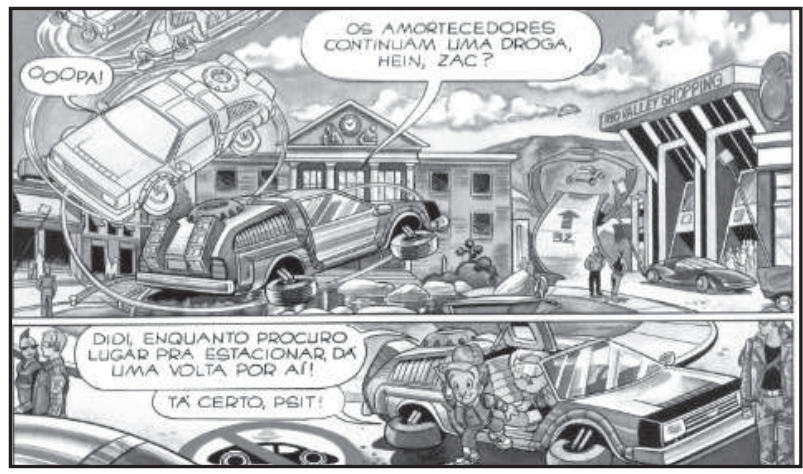

Figura 5 - HQ Didi Volta Para o Futuro II Fonte: Didi Volta Para o Futuro (1991, p.21).

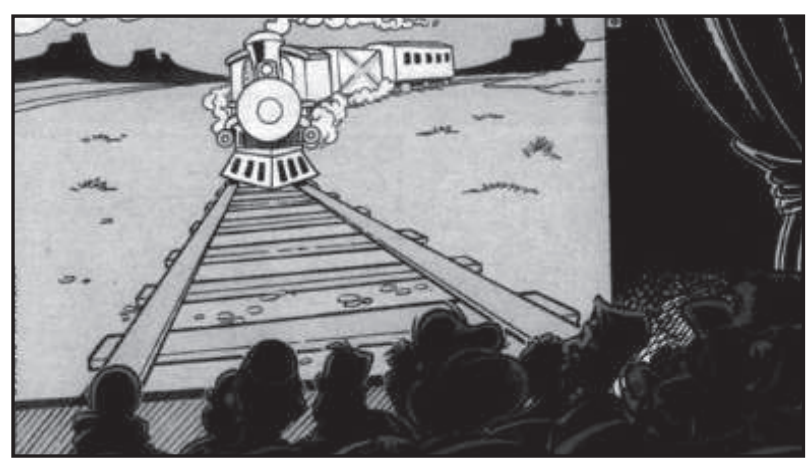

Figura 7 - HQ Os Irmãos Lumière

Fonte: As Aventuras dos Trapalhões, Ed. 27.

obra através de uma releitura dos seus pressupostos estéticos". Os Trapalhões, com a disseminação de sua linguagem, conseguiam transformar o drama numa comédia, assim como acontecia com histórias como O Cangaceiro Trapalhão (Brasil, 1983) nos cinemas ou O Poderoso Trapalhão (1991) nos quadrinhos.

\section{Propostas para a educação}

A metodologia proposta é para as escolas de educação infantil nas quais poderiam ser trabalhadas diversas histórias das HQs do grupo. Para a proposta elaborada neste artigo selecionou-se o filme Edward: Mãos de Tesoura (1990) e a HQ: Eduardedé, Mãos de Tesoura! (1993). A partir destas duas obras são sugeridas atividades a serem realizadas pelos professores dos anos iniciais do Ensino Fundamental com o objetivo de despertar o interesse pelo cinema.

Barbosa et al. (2004) observam que de uma maneira geral existem diversos ciclos escolares 


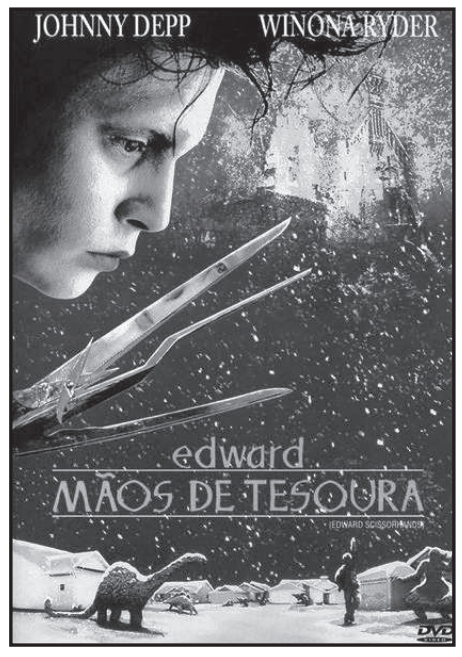

Figura 9 - Capa do Filme

Fonte: Edward mãos de tesoura (2012).

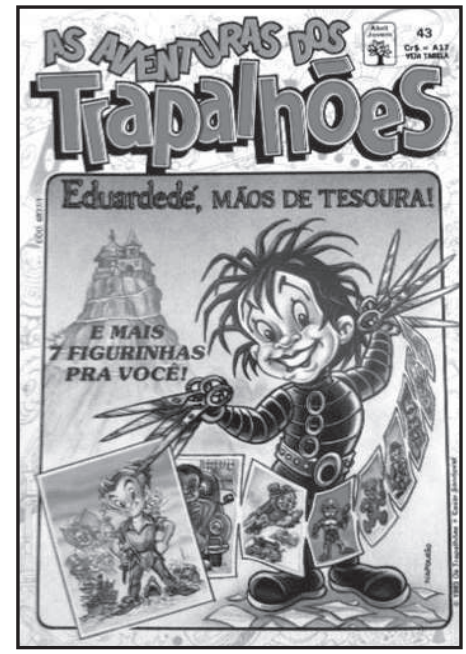

Figura 10 - Capa da HQ

Fonte: As Aventuras dos Trapalhões, Ed. 43 (pré-escolar, ensino fundamental, ensino médio) e que cada aluno, de acordo com a idade, terá um tipo de desenvolvimento intelectual e recepção aos quadrinhos. Esta contribuição aqui proposta se baseia apenas nos anos iniciais do Ensino Fundamental (1.a a 4.a série). Nessa fase a criança começa a deixar de "ver a si mesma" como o centro do mundo e inicia a incorporação dos demais colegas e do seu ambiente evoluindo num processo de socialização.

Segundo Simão (2012, p. 630), o essencial de um "professor da educação infantil se concreta em transformar conhecimento em sabedoria e a sabedoria em conhecimento e tudo de forma criativa". A autora ainda diz que é importante a criança ser estimulada a perguntar, fazer questionamentos, ficar interessada pelo que vê e ampliar cada vez mais o seu repertório cultural. É dentro desse contexto educacional que se pensou na utilização das HQs d'Os Trapalhões como incentivo para o gosto e o interesse pelo cinema.

O filme Edward: Mãos de Tesoura (1990), do diretor Tim Burton, trata de uma história na qual uma vendedora de cosméticos acidentalmente conhece e descobre Edward (interpretado pelo ator Johnny Depp). Ele mora num castelo e foi criado por um inventor que lhe deu mãos em formato de lâminas. Isso faz com que se afaste dos humanos; porém, ele consegue criar cortes de cabelo diferentes e começa a podar a vegetação da cidade. O que mais chama a atenção na película é a ingenuidade da personagem principal e a forma como a sociedade começa a enxergá-lo por ser diferente.

A HQ: Eduardedé, Mãos de Tesoura! (1993) trabalha com a paródia do filme do diretor Tim Burton. Os quatro integrantes de Os Trapalhões dão vida para essa história que se desenrola agora em HQ. É notável a presença da intertextualidade com o filme: dos argumentos, das personagens e do local no qual é ambientada a história original.

A metodologia de proposta para esta atividade são explicadas em etapas a seguir:

1) exibição do filme: o professor já deveria ter um prévio conhecimento sobre o conteúdo do filme. Buscar informações do filme na internet, em revistas, em livros etc. É o professor que passará informações sobre o filme aos alunos. É esse interesse que deve ser despertado no aluno. Segundo Pereira (2012, p. 1), quando um professor consegue estabelecer "relações entre o tema do filme e o assunto do estudo, ampliam-se as perspectivas do debate para além das expectativas, pois o filme tem a capacidade de mexer com as emoções e com o intelecto de quem o assiste"; 
2) discussão com os alunos sobre o filme e a relação com a matéria estudada. É o momento também em que o professor propõe uma discussão após o filme, na qual são abordadas questões sobre a história, a relação das personagens, enredo e roteiro do filme, sua relevância com a sociedade atual etc.;

3) leitura da História em Quadrinhos que faz o intertexto com o filme. Em seguida os alunos fazem a leitura da HQ, que pode ser escaneada ou fotocopiada, até mesmo postada num blog elaborado pelo professor no qual os arquivos poderiam ser baixados pelos alunos em laboratórios de informática da escola. De accordo com Pereira (2012), o cinema - e neste contexto, os livros e as histórias em quadrinhos - faz com que os espectadores/ leitores mergulhem no universo das personagens do enredo e também faz a criança e o adolescente ficarem situados num universo imaginário que contribui para a construção de histórias. A própria leitura dos quadrinhos estimularia e deixaria as crianças mais a vontade para entender o filme por meio da paródia criada, e pelo fato de os personagens terem uma linguagem infantil nas histórias o que entra em contexto com a realidade da criança;

4) atividade a ser realizada. O professor deve passar aos alunos os critérios de avaliação. A partir desta atividade, várias coisas poderão ser realizadas, como, por exemplo, fazer a relação da HQ com a história do filme, fazer desenhos que representem a HQ e o filme, leituras de textos pertinentes ao contexto da aula e da HQ e do filme, representação teatral da história, elaboração de redação acerca da narrativa do filme e da HQ, entre muitas outras atividades que podem ser realizadas a partir da criatividade do professor. Os trabalhos poderiam ser expostos em murais ou apresentados em sala de aula pelos alunos;

5) avaliação. É o momento em que o professor faz a avaliação da atividade realizada seguindo seus critérios avaliativos e já passados aos alunos na etapa anterior;

6) retorno da avaliação com os alunos. É quando o professor faz a devolutiva dos trabalhos aos alunos e discute com eles a atividade já realizada. Além disso, é importante que o professor ouça e dialogue com os alunos sobre a atividade realizada para melhorias na próxima vez em que for aplicada.

Esta atividade se traduz nas palavras de Bari (2008, p. 215), quando ressalta que: "a geração de jovens que cresceram sob a égide da informática se identifica com a mídia quadrinhística, sentindo-se atraída também pelas possibilidades que cada leitor tem de criar suas próprias narrativas por meio desta linguagem."

Esta não chega a ser uma proposta inovadora e muito menos tem a pretensão de esgotar o assunto sobre o tema, mas surge com o objetivo de ser implantada em escolas de educação básica (anos iniciais do Ensino Fundamental) do município de Blumenau/SC. Barbosa et al. (2004) dizem que não existem regras para a utilização dos quadrinhos em sala de aula, porém o bom aproveitamento vai de acordo com a criatividade do professor e a capacidade de saber usá-los no processo de ensino e aprendizagem.

\section{Considerações finais}

As considerações deixadas aqui visam contribuir no processo de ensino e aprendizagem, semeando propostas eideias aos professores para que utilizem HQs que fazem uma intertextualidade com o cinema e, que estas, possam despertar o interesse por obras audiovisuais e que contribuam na formação cultural das crianças e dos adolescentes.

Barbosa et al. (2004, p. 7) entendem que "as histórias em quadrinhos, além de serem um dos primeiros veículos a caminhar para a padronização dos conteúdos, também incorporaram a globalização econômica em seus processos de produção", por meio disso é que se conseguiu um mercado cada vez mais competitivo e promissor na área.

A partir da proposta aqui apresentada, sugere-se que o professor pesquise outras histórias 
em quadrinhos e filmes com diferentes temáticas que também poderiam ser trabalhadas em sala despertando o interesse pelo cinema nas crianças e nosadolescentes.

Encerra-se este estudo com as palavras de Carvalho (2006, p. 30) quando afirma que os valores de um quadrinho é muito mais importante que o número de vendas, "isso porque, além de meio de comunicação de massa, entretenimento, arte, as HQs podem ser uma excelente ferramenta na sala de aula."

\section{Referências}

ADORO CINEMA. Disponível em: < http://www. adorocinema.com/filme s / f ilm e - 27624 / f o to s / detalhe $/$ ?cmediafile $=20140763>$ Acesso em: 08 set. 2012 .

ANDRAUS, G. As histórias em quadrinhos como informação imagética integrada ao ensino universitário. 2006. Tese (Doutorado em Ciências da Comunicação) - Universidade de São Paulo, São Paulo, 2006.

AS AVENTURAS DOS TRAPALHÕES. Disponível em: <http://www.gibizinho. com/media/catalog/product/ cache/1/image/9df78eab33525d08d6e 5fb8d27 136e95/a/v/aventuras_dos_trapalhoes10.0001. jpg>. Acesso em: 26 ago 2012.

BARBOSA, A.; RAMOS, P.; VILELA, T.; RAMA, A.; VERGUEIRO, W. (Orgs.). Como usar as histórias em quadrinhos na sala de aula. São Paulo: Contexto, 2004.

BARI, V. A. O potencial das histórias em quadrinhos na formação de leitores: busca de um contraponto entre os panoramas culturais brasileiro e europeu. 2008. Tese (Doutorado em Ciências da Comunicação) - Universidade de São Paulo, São Paulo, 2008.

BELLONI, M. L. Crianças e mídias no Brasil: cenários de mudanças. Campinas, SP: Papirus, 2010.

CARVALHO, D. A educação está no gibi. Campinas, SP: Papirus, 2006.
CIRNE, M. A explosão criativa dos quadrinhos. 5.ed. Petrópolis, RJ: Vozes, 1977.

CIRNE, M. Quadrinhos, sedução e paixão. Petrópolis, RJ: Vozes, 2000.

DIDI \& LILI. Disponível em: < http:/ / www.escala. c o m . b r / r e v is t a 1 / R - DIDILILI04_7897763452848c. gif $>$. Acessado em: 26 ago 2012.

D’OLIVEIRA, G. F. Saberes enquadrados: histórias em quadrinhos e (re)construções identitárias. 2009. Tese (Doutorado em Ciências da Comunicação) - Universidade de São Paulo, São Paulo, 2009.

FIELD, S. Manual do roteiro: os fundamentos do texto cinematográfico. Rio de Janeiro: Objetiva, 2001.

GUIA DOS QUADRINHOS. Disponível em HYPERLINK "http://www.guiadosquadrinhos. com.br" www.guiadosquadrinhos. com.br. Acessos intermediários em jul. 2012.

GUIMARÃES, D. A. D. The Spirit, de Frank Miller: a opção estética e o domínio técnico na transcrição fílmica da obra de Will Eisner. In: ENCONTRO DA COMPÓS, 19., 2010, Rio de Janeiro. Anais... Rio de Janeiro: PUC/ RJ, jun. 2010.

ILUSTRADA NO CINEMA. Disponível em: < http:// ilustradanocinema.folha.blog.uol.com.br/images/tremv. jpg >. Acesso em: 26 ago. 2012.

JENKINS, H. Cultura da convergência. 2.ed. São Paulo: Aleph, 2009.

MENDONÇA, M. R. S. Ciência em quadrinhos: recurso didático em cartilhas educativas. 2008. Tese (Doutorado em Linguística) - Universidade Federal de Pernambuco, Recife, 2008.

NOGUEIRA, L. Manuais de cinema I: laboratório de guionismo. Portugal: LabCom Books, 2010. 
OS TRAPALHÕES. Capa de Gibi. Disponível em: $<$ http:/ / c o n t r ave r sa o. c o m / w p -content/uploads/2012/04/OS-TRAPALHÕES-36_Bloch-517x800. jpg>. Acesso em: 26 ago. 2012.

OS TRAPALHÕES. Site dedicado ao Grupo Os Trapalhões. Disponível em: <http://www.ostrapalhoes. com/p/quadrinhos.html>. Acesso em: 27 jul. 2012.

PACHECO, E. D. Comunicação, educação e arte na cultura infanto-juvenil. São Paulo: Loyola, 1991.

PATATI, C.;BRAGA,F.Almanaque dos quadrinhos: 100 anos de uma mídia popular. Rio de Janeiro: Ediouro, 2006.

PEREIRA, T. R. A escola infantil e o cinema. Revista Eletrônica Zero-a-Seis - Revista editada pelo Núcleo de Estudos e Pesquisas de Educação na Pequena Infância da UFSC, Florianópolis/SC, v.1, n.26, 2012. Disponível em: <http://www.periodicos.ufsc.br/index.php/zeroseis/ article/view/25344/22275> Acesso em: 28 ago. 2012.

RABAÇA, C. A.; BARBOSA, G. G. Dicionário de comunicação. 2.ed. rev. e atual. Rio de Janeiro: Campus, 2001.

RAMOS, J. M. O. Cinema, televisão e publicidade: cultura popular de massa no Brasil nos anos 1970-1980. 2.ed. São Paulo: Annablume, 2004.

RETRATOS DA LEITURA NO BRASIL. Terceira edição da pesquisa sobre a leitura no Brasil. Instituto Pró-Livro e Ibope Inteligência. Disponível em: < http:/ / www.cultura.gov.br/site/wp-content/uploads/2012/03/ Retratos-da-leitura-no-Brasil.pdf $>$. Acesso em: 26 ago 2012.

RIZZO JÚNIOR, S. A. Educação audiovisual: uma proposta para a formação de professores de ensino fundamental e de ensino médio no Brasil. 2011. Tese (Doutorado em Meios e Processos Audiovisuais) - Universidade de São Paulo, São Paulo, 2011.
SANTOS, R. E. A história em quadrinhos na sala de aula. In: CONGRESSO BRASILEIRO DE CIÊNCIAS DA COMUNICAÇÃO, 26., 2003, Belo Horizonte. Anais... Belo Horizonte, 02 a 06 set. 2003. (1 CD-ROM).

SIMÃO, V. L. Formação continuada e várias vozes do professorado de educação infantil de Blumenau: uma proposta vinda de dentro. Revista Atos de Pesquisa em Educação - PPGE/ME FURB, Blumenau/SC, v. 7, n. 2, maio/ago. 2012.

VERGUEIRO, W. As histórias em 10 quadrinhos. 26 out. 2004. Disponível em: <http://www1.folha.uol. com.br/folha/sinapse/ult1063u951.shtml>. Acesso em: 20 jul. 2012.

VERGUEIRO, W.; SANTOS, R. E. A pesquisa sobre histórias em quadrinhos na Universidade de São Paulo: análise da produção de 1972 a 2005. UNIrevista, v. 1, n. 3 , jul. 2006

VIEIRA, D.; VELOSO, L. F. História em quadrinhos no ensino de jovens com TDAH. In: SEMINÁRIO INTERNACIONAL DE EDUCAÇÃO: DOCÊNCIA NOS SEUS MÚLTIPLOS ESPAÇOS, 16., 2011, Cachoeira do Sul. Anais... Cachoeira do Sul, 06 a 08 jul. 2011.

VILELA, M. T. R. A utilização dos quadrinhos no ensino de história: avanços, desafios e limites. 2012. Dissertação (Mestrado em Educação) - Universidade Metodista de São Paulo, São Bernardo do Campo, 2012.
Recebido: 23/09/2012

Received: 09/23/2012

Aprovado: 20/11/2012

Approved: 11/20/2012 